\title{
The Profile of Clinically Diagnosed New Type 2 Diabetes among Asian Indians
}

\author{
Arun Raghavan, Arun Nanditha, Krishnamoorthy Satheesh, Priscilla Susairaj, Ramachandran Vinitha, Chamukuttan Snehalatha \\ and Ambady Ramachandran* \\ India Diabetes Research Foundation and Dr. A. Ramachandran's Diabetes Hospitals, Chennai, India \\ ${ }^{\star}$ Corresponding author: Prof. A. Ramachandran, President, India Diabetes Research Foundation Chairman, Dr. A. Ramachandran’s Diabetes Hospitals, 110, Anna Salai, \\ Guindy, Chennai - 600 032, India; Phone: +91 44 42162003; E-mail: dr.ramachandran@ardiabetes.org
}

Received: August 05, 2020; Accepted: August 12, 2020; Published: August 17, 2020

\begin{abstract}
Aim: To study the clinical and metabolic characteristics of newly diagnosed type 2 diabetes (T2DM) in urban clinics (CDD) and also to compare with the screen detected new diabetes cases (SDD) during an urban population survey.

Methods: Newly diagnosed T2DM (aged 20-60 years, n=741), based on blood glucose and Glycosylated haemoglobin (HbA1c) of $\geq 6.5 \%$ (48 mmol/mol) were selected. Demography, anthropometry, blood pressure, glycaemic and lipids profiles were analysed. Relevant statistical tests were used for group comparisons.
\end{abstract}

Results: Both groups had young age $(45.0 \pm 8.6$ years) at diagnosis. Fasting blood glucose $(\mathrm{p}<0.05)$ and $\mathrm{HbA1c}(\mathrm{p}<0.0001)$ were higher in CDD. Mean values of HbA1c were $9.1 \pm 2.3 \%(76 \pm 20 \mathrm{mmol} / \mathrm{mol})$ in CDD and $8.3 \pm 2.4 \%(67 \pm 19 \mathrm{mmol} / \mathrm{mol})$ in SDD (p<0.0001). Values of HbA1c were higher than $\geq 9.0 \%$ (75 mmol $/ \mathrm{mol})$ in $44.6 \%$ of CDD versus $26.4 \%$ of SDD ( $\mathrm{C}=4.60, \mathrm{p}<0.0001)$. SDD had higher body mass index ( $<<0.0001$ ), abdominal obesity $(\mathrm{p}<0.005)$, hypertension $(\mathrm{p}<0.0001)$, cholesterol $(\mathrm{p}<0.005)$ and low density lipoprotein cholesterol $(\mathrm{p}<0.05)$ than $C D D$.

Conclusion: Both groups had young age at diagnosis. CDD had more severe glycaemia than SDD, probably suggesting that the clinic visits were delayed and therefore had longer period of undiagnosed diabetes. In comparison to CDD, SDD had higher metabolic abnormalities although the HbA1c values were lower.

Keywords: Newly diagnosed type 2 diabetes, South Asians, Clinical characteristics, HbA1c, Metabolic abnormalities

\section{Introduction}

Many developing countries show a rising trend in the prevalence and also in the incidence of type 2 diabetes T2DM [1-3]. Recently, a systematic review of studies on trends in the incidence of T2DM among adults in developed countries has shown that between 2006 and $2014,27 \%$ of the reported populations had a stable incidence over time, while $36 \%$ reported a declining trend and $36 \%$ reported an increasing trend in the incidence of T2DM [4]. The declining trend in the incidence has been shown mostly in the developed countries. A huge clinical burden of newly diagnosed T2DM is present in developing countries. There is only limited real-world data describing the clinical characteristics of such patients [5].

The prevalence of diabetes is increasing rapidly in India, which is estimated to be 77 million adults in 2019 [1]. A recent epidemiological study done in urban India showed that, the prevalence and incidence of diabetes have increased significantly in all areas, including the Peri Urban Villages (PUV) of Tamil Nadu [2]. Using the data from the two studies conducted in 2006 [6] and 2016 [2] to estimate the incidence of diabetes, it was noted that, a sharper increase in the incidence occurred in the urban areas when compared with the villages [2]. A similar observation was made in the INdia DIABetes (INDIAB) study conducted in 15 states of India [7] as well as in a cohort study of 10 years follow-up in the urban area in southern India [8].

Several peculiar features are seen among the newly diagnosed South Asian populations with T2DM such as, younger age at onset, delayed clinical diagnosis due to lack of public awareness regarding the disease, reluctance to undergo periodic medical check-up and a long asymptomatic phase of T2DM [3,9]. The diagnosis of diabetes is often delayed, more so in the developing societies. Previous studies have described the characteristics of patients attending the clinics, who are under treatment $[3,6,8]$. There is sparse data on the profile of clinically diagnosed new T2DM patients in India.

The aim of this project was to study the clinical and metabolic characteristics of newly diagnosed adult T2DM patients from different clinics (CDD). We compared the profile with that of new T2DM identified during an epidemiological screening of urban population (SDD) [2].

\section{Methods and Materials}

\section{Study Subjects}

This is a study of newly diagnosed adult T2DM from 12 different centres located in four southern states of India. Patients with a previous 
history of diabetes or had taken anti-diabetes treatment were excluded from the study by the clinicians. Persons with prediabetes were also excluded. Details of men and women in the selected age group, who were treatment naive were collected and analysed. For comparison, a group of newly detected T2DM subjects from an epidemiological survey of the urban population was taken.

All participants reported on fasting on the day of testing. In the clinics, the diagnosis of diabetes was based on blood glucose (fasting blood glucose $\geq 7.0 \mathrm{mmol} / \mathrm{l}$ and/2 hour Post Prandial Glucose (PPG) $\geq 11.1 \mathrm{mmol} / \mathrm{l}$ ) [10]. In the epidemiological study, diagnosis was made based on fasting and $2 \mathrm{~h}$ Post Blood Glucose (PBG) values. The 2 hour PBG was measured after giving $75 \mathrm{~g}$ of glucose load. We selected only patients who had an $\mathrm{HbAlc}$ value of $\geq 6.5 \%$ ( $48 \mathrm{mmol} / \mathrm{mol}$ ) [11]. The total number of subjects analysed was 741 , comprising of 514 from CDD and 227 from SDD; Identifier: NCT03490136 [2].

All centres followed uniform and standardised procedures for metabolic and clinical assessments. The study details and methodology were discussed in a meeting of the investigators, participating physicians and the researchers prior to the commencement of the study.

The Ethics Committee of the India Diabetes Research Foundation and Dr. A. Ramachandran's Diabetes Hospitals approved the study. A written informed consent was obtained from all participants prior to the enrollment, at all centres. It was also agreed that the identity of the participants would not be disclosed. All study procedures were carried out in accordance to the ethical guidelines.

\section{Clinical Assessments}

Age, sex and presence of family history of diabetes were collected. Height was measured to the nearest centimeter using a stadiometer with the patient standing erect. Weight was measured to the nearest $0.1 \mathrm{~kg}$ using a digital weighing scale. Body mass index (BMI) was calculated as weight in kilograms divided by the square of height in meters. Generalized obesity was defined as BMI $\geq 23.0 \mathrm{~kg} / \mathrm{m}^{2}$, BMI between $\geq 23.0$ and $24.9 \mathrm{~kg} / \mathrm{m}^{2}$ was considered overweight, and BMI $\geq 25.0 \mathrm{~kg} / \mathrm{m}^{2}$ was defined as obese. Waist circumference (WC), the smallest girth between the coastal margin and the iliac crest, was measured. Abdominal obesity was indicated by WC of $\geq 90 \mathrm{~cm}$ for men and $\geq 80 \mathrm{~cm}$ for women. Blood pressure was measured in the sitting position using the electronic measuring device (Omron HEM 7132; Omron, Tokyo, Japan). An average of two readings taken at 5-minutes' interval was recorded. Persons with a history of hypertension and those with newly diagnosed diabetes with blood pressure readings $\geq 140 / 90 \mathrm{mmHg}$ were categorized as hypertensive. All the clinical and metabolic details were recorded in a standardised questionnaire.

\section{Biochemical Assessments}

Glucose was measured in the respective study centres by the glucose oxidase method. Other biochemical parameters such as HbA1c and lipid profile were estimated at the central laboratory (Dr. A. Ramachandran's Diabetes Hospitals, Chennai). Glycosylated haemoglobin (HbA1c) was measured by immunoturbidimetry (TINA-
QUANT II; Roche Diagnostics Corporation, Germany); a procedure certified by the National Glycohemoglobin Standardization Program. Fasting serum lipid profile was estimated by standard enzymatic procedures using the reagents of Roche Diagnostics, Germany. HDLc was estimated by the direct assay. Samples were shipped to the central laboratory between $2^{\circ}$ and $8^{\circ} \mathrm{C}$ on the same day of collection.

\section{Statistical Analyses}

Data are presented as mean \pm standard deviation (SD) for continuous variables with a normal distribution, as median with interquartile range for skewed continuous variables and as number and frequency (\%) for categorical variables. Independent samples $t$ test, chi-square or $\mathrm{Z}$ - test were used to assess group differences for continuous variables and categorical variables respectively. Mann Whitney $\mathrm{U}$ test was used for skewed variables. A $p$ value of $<0.05$ was considered statistically significant. Statistical analyses were performed using SPSS version 21.0.

\section{Results}

Table 1 shows the demographic and anthropometric characteristics of the two groups with newly diagnosed T2DM. CDD had higher percentage of men than SDD $(\mathrm{p}<0.05)$. Both groups had similar mean age at diagnosis (45.2 \pm 8 years). The mean BMI was higher in SDD $(\mathrm{p}<0.0001)$. Prevalence of overweight and obesity were similar in both the groups. Women in SDD had higher WC $(\mathrm{p}<0.005)$ and the percentage of abdominal obesity $(\geq 80 \mathrm{~cm})$ was also higher in SDD

Table 1: Demographic and anthropometric characteristics of the study groups with newly diagnosed type 2 diabetes.

\begin{tabular}{|c|c|c|}
\hline & $\begin{array}{l}\text { Clinically diagnosed } \\
\qquad \begin{array}{c}(\mathbf{n}=514) \\
\text { (CDD) }\end{array}\end{array}$ & $\begin{array}{l}\text { Diagnosed during } \\
\text { screening } \\
(\mathbf{n}=\mathbf{2 2 7}) \\
\text { (SDD) }\end{array}$ \\
\hline Men (n, \%) & $313(60.9)^{*}$ & $117(51.5)$ \\
\hline Positive family history of DM (n, \%) & $175(34.0)$ & $92(40.5)$ \\
\hline Age (yrs) & $45.2 \pm 8.6$ & $45.0 \pm 8.6$ \\
\hline BMI $\left(\mathbf{k g} / \mathbf{m}^{2}\right)$ & $25.3 \pm 3.7$ & $27.3 \pm 4.6^{\$}$ \\
\hline Nonobese $\leq 22.9(\mathrm{n}, \%)$ & $101(19.6)$ & $39(17.2)$ \\
\hline Overweight \& Obese $\geq 23.0(n, \%)$ & $413(80.4)$ & $188(82.8)$ \\
\hline \multicolumn{3}{|l|}{ Waist Circumference $(\mathrm{cm})$} \\
\hline Men $(\mathrm{cm})$ & $91.9 \pm 8.9$ & $93.0 \pm 9.8$ \\
\hline Women $(\mathrm{cm})$ & $88.7 \pm 10.6$ & $91.8 \pm 10.8^{\#}$ \\
\hline Men $\geq 90(n, \%)$ & $195(37.9)$ & $73(32.2)$ \\
\hline Women $\geq 80(\mathrm{n}, \%)$ & $164(31.9)$ & $94(41.4)^{*}$ \\
\hline \multicolumn{3}{|l|}{ Blood Pressure } \\
\hline Systolic Blood Pressure (mm Hg) & $128 \pm 13$ & $127 \pm 18$ \\
\hline Diastolic Blood Pressure (mm Hg) & $81 \pm 9$ & $86 \pm 11^{s}$ \\
\hline $\mathrm{BP}>140 / 90 \mathrm{~mm} \mathrm{Hg}(\mathrm{n}, \%)$ & $54(10.5)$ & $44(19.4)^{\#}$ \\
\hline
\end{tabular}

Data are presented as mean + SD for continuous variables with normal distribution and as frequency (\%) for categorical variables. Independent samples t test and chi-square test or $\mathrm{Z}$ test were used to test inter group differences for continuous variables and categorical variables.

CDD vs. $\mathrm{SDD}={ }^{*} \mathrm{p}<0.05 ;{ }^{*} \mathrm{p}<0.005 ;{ }^{\$} \mathrm{p}<0.0001$.

CDD, Clinically Diagnosed Diabetes; SDD, Screen Detected Diabetes; BMI, Body Mass Index; BP, Blood Pressure. 
Table 2: Metabolic profile of the study groups with newly diagnosed type 2 diabetes.

\begin{tabular}{|l|c|c|}
\hline & $\begin{array}{c}\text { Clinically diagnosed } \\
(\mathbf{n = 5 1 4}) \\
(\mathbf{C D D})\end{array}$ & $\begin{array}{c}\text { Diagnosed during } \\
\text { screening } \\
(\mathbf{n}=\mathbf{2 2 7}) \\
\text { (SDD) }\end{array}$ \\
\hline Glycemic Parameters & $9.8 \pm 3.3^{*}$ & $9.3 \pm 3.2$ \\
\hline Fasting blood glucose $(\mathrm{mmol} / \mathrm{l})$ & $15.4 \pm 4.4$ & $15.3 \pm 4.2$ \\
\hline 2 hour post blood glucose $(\mathrm{mmol} / \mathrm{l})$ & $9.1 \pm 2.3(76.1 \pm 19.8)^{\mathrm{s}}$ & $8.3 \pm 2.4(66.8 \pm 19.0)$ \\
\hline HbAlc \% (mmol/mol) & $349(67.9)^{\mathrm{s}}$ & $96(42.3)$ \\
\hline HbAlc $\geq 8.0 \%(64 \mathrm{mmol} / \mathrm{mol})(\mathrm{n}, \%)$ & $229(44.6)^{\mathrm{s}}$ & $60(26.4)$ \\
\hline HbAlc $\geq 9.0 \%(75 \mathrm{mmol} / \mathrm{mol})(\mathrm{n}, \%)$ & 243 & 222 \\
\hline Lipid Profile $(\mathbf{n})$ & $1.8(1.3-2.7)$ & $1.8(1.3-2.8)$ \\
\hline Triglyceride $(\mathrm{mmol} / \mathrm{l})$ & $4.8 \pm 1.0$ & $5.1 \pm 1.1^{*}$ \\
\hline Total Cholesterol $(\mathrm{mmol} / \mathrm{l})$ & $3.4 \pm 0.9$ & $3.6 \pm 1.0^{*}$ \\
\hline LDLc (mmol/l) & $1.0 \pm 0.3$ & $1.0 \pm 0.2$ \\
\hline HDLc (mmol/l) & \\
\hline
\end{tabular}

Data are presented as mean \pm SD for continuous variables with a normal distribution, as median with interquartile range for skewed continuous variables and as frequency (\%) for categorical variables. Independent samples t test and chi-square test or $\mathrm{Z}$ test were used to test intergroup differences for continuous variables and categorical variables. Mann Whitney $\mathrm{U}$ test was used for skewed variables.

CDD vs. $\mathrm{SDD}={ }^{*} \mathrm{p}<0.05 ;{ }^{*} \mathrm{p}<0.005 ;{ }^{\circledR} \mathrm{p}<0.0001$

CDD: Clinically Diagnosed Diabetes; SDD: Screen Detected Diabetes; HbAlc: Glycosylated hemoglobin; LDLc: Low Density Lipoprotein Cholesterol; HDLc: High Density Lipoprotein Cholesterol.

$(\mathrm{p}<0.05)$. SDD had higher mean diastolic blood pressure $(\mathrm{p}<0.0001)$ and higher percentage of hypertension $(\mathrm{p}<0.005)$.

Table 2 shows the metabolic profile of the study groups. SDD had lower FBG $(p<0.05)$ and HbAlc $(p<0.0001)$ when compared with CDD. Among the total cohort of 741, 445 (60.1\%) had HbAlc values $\geq 8.0 \%$ (64 mmol/mol), of which 289 (39.0\%) had values $\geq 9.0 \%$ (75 $\mathrm{mmol} / \mathrm{mol})$.

It was observed that a larger proportion of CDD (67.9\%) had values of $\geq 8.0 \%(64 \mathrm{mmol} / \mathrm{mol})$ versus $42.3 \%$ of SDD ( $\mathrm{z}=6.47, \mathrm{p}<0.0001)$. HbAlc values $\geq 9.0 \%(75 \mathrm{mmol} / \mathrm{mol})$ were present in $44.6 \%$ in CDD versus $26.4 \%$ in $\operatorname{SDD}(\mathrm{z}=4.60, \mathrm{p}<0.0001)$. Among the lipid variables, total cholesterol $(\mathrm{p}<0.005)$ and Low Density Lipoprotein cholesterol $(\mathrm{LDLc})(\mathrm{p}<0.05)$ were higher in SDD.

\section{Discussion}

There have been many reports highlighting the differences in the clinical profile of diabetes between South Asians and the western populations [12,13]. But, there is sparse data on the clinical and metabolic characteristics of newly diagnosed T2DM from India. In this communication we report the clinical and metabolic characteristics of newly diagnosed diabetes patients recruited from different centres in southern India (CDD). The group represents the urban population with diabetes. We compared its clinical profile with a group of undiagnosed diabetes detected during an urban epidemiological survey (SDD).

In our study, the mean age of the newly diagnosed T2DM in both the groups was similar $(45.2 \pm 8.6$ and $45.0 \pm 8.6$ years in CDD and SDD respectively). Another large, multicentre, cross-sectional study among diabetes patients in India also showed that the mean age at onset of T2DM was $45.4 \pm 10.9$ years which was similar to the observation made in our study [14]. This was significantly lower than that reported among the newly diagnosed T2DM cases in the United States (55.6 \pm 13 years) [5]. Similarly, in two large multi-ethnic studies from UK $[15,16]$, the age at diagnosis of T2DM was found to be lower $(51.5 \pm 10.42$ and $52.6 \pm 13.5$ years respectively) in the South Asian population when compared to the White population (58.9 \pm 10.09 and $63.3 \pm 13.8$ years respectively). South Asians develop T2DM at least a decade earlier.

Lower BMI with higher HbAlc in the CDD compared to SDD could possibly be due to a reduction in weight usually associated with moderate to high levels of undetected hyperglycaemia. In an earlier study, we had observed that more than $20 \%$ of the cases had weight loss prior to the clinical diagnosis of T2DM [17]. Among the Asian populations, Indians have a reluctance to undergo regular health check-up and medical consultation is often sought only when the symptoms or related problems arise due to diabetes [9]. Similar observation had been reported earlier in migrant Asian populations in western countries $[15,18]$. In the UK, a multiethnic South London study mentioned above showed that HbAlc levels were higher in South Asians than in the Europeans at an early period after the diagnosis. This was partially attributed to a delayed diagnosis in the Asians [15]. In our study, the significantly higher FBG and HbAlc observed in CDD could be related to a delay in the diagnosis of diabetes when compared with those diagnosed during an epidemiological screening. There is a higher likelihood of a few CDD patients having taken treatment for hypertension and hyperlipidaemia prior to visiting a diabetes clinic.

In our study, $44.6 \%$ of the patients had significantly higher $\mathrm{HbAlc} \geq 9.0 \%$ ( $75 \mathrm{mmol} / \mathrm{mol})$ when compared with $21.7 \%$ of the newly diagnosed patients in the clinics in USA [5]. There may be a number of reasons for high $\mathrm{HbAlc}$ in newly detected diabetes. One important reason could be longer periods of undetected T2DM in our population, partially due to the delay on the part of the patients to seek medical help. In India, a larger percentage of men report for medical consultation than women. Therefore, the proportion of men was more among the clinically diagnosed cases.

In an earlier study, we had noted that T2DM remains asymptomatic for a longer period of time and many develop complications such as retinopathy even before diagnosis [19]. We did not record the presence of symptoms or complications in this study.

Hypercholestremia seen among the newly diagnosed patients may also be related to the delayed diagnosis of diabetes and higher blood glucose levels. In SDD, screening for diabetes was done among adults with neither a previous history nor the presence of symptoms of diabetes. There is a higher chance of early detection of diabetes among this group than in the clinic diagnosed cases. The likelihood of early detection of hypertension is also higher when screening is done.

Our study describes the clinical and metabolic features of newly diagnosed T2DM in the clinics. The differences with the screen detected diabetes in the population probably indicate late diagnosis in the clinics. 


\section{Declarations}

\section{Funding}

The study was funded by India Diabetes Research Foundation, Chennai.

\section{Conflict of interest}

None

\section{Ethics approval}

The study was approved by the Ethics Committee of the India Diabetes Research Foundation and Dr. A. Ramachandran's Diabetes Hospitals.

\section{Consent to participate}

A written informed consent was obtained from all participants prior to the enrollment in the respective studies.

\section{Authors' contributions}

Arun R, AR, CS, AN and RV contributed to the study design, developed the protocol, supervised the study, drafted the manuscript and revised it with critical input. AR, CS, Arun R, PS and KS contributed to data preparation and analyses. KS and PS participated and coordinated the field work and data collection. All authors have read and approved the final draft of the manuscript.

\section{Acknowledgements}

The authors acknowledge the support rendered by the study physicians of various hospitals for providing the data source of the clinic patients. The help rendered by Mr.M.Karthikeyan and the epidemiology team of the India Diabetes Research Foundation in coordinating the epidemiological screening is greatly acknowledged. We are grateful to all the participants of the study for their cooperation and support.

\section{Abbreviation}

BMI: Body Mass Index

CDD: Clinically Diagnosed Diabetes

FBG: Fasting Blood Glucose

HbA1c: Glycosylated Haemoglobin

PBG: Post Blood Glucose

PPG: Post Prandial Blood Glucose

SDD: Screen Detected Diabetes

T2DM: Type 2 Diabetes

WC: Waist Circumference

\section{References}

1. International Diabetes Federation. IDF Diabetes Atlas, $9^{\text {th }}$ edn. Brussels, Belgium: 2019. Available at: http: //www.diabetesatlas.org. Last accessed on $11^{\text {th }}$ March 2020.

2. Ramachandran A, Snehalatha C, Shaw JE, Susairaj P, et al. (2019) Response to Comment on Nanditha et al. Secular TRends in DiabEtes in India (STRiDE-I): Change in Prevalence in 10 Years Among Urban and Rural Populations in Tamil Nadu. Diabetes Care 42: 476-485. [crossref]

3. Misra A, Ramchandran A, Jayawardena R, Shrivastava U, et al. (2014) Diabetes in South Asians. Diabet Med 31: 1153-62. [crossref]

4. Magliano DJ, Islam RM, Barr ELM, Gregg EW, et al. (2019) Trends in incidence of total or type 2 diabetes: systematic review. BMJ 366: 15003. [crossref]

5. Pantalone KM, Hobbs TM, Wells BJ, Kong SX, et al. (2016) Changes in characteristics and treatment patterns of patients with newly diagnosed type 2 diabetes in a large united states integrated health system between 2008 and 2013. Clin Med Insights Endocrinol Diabetes 9: 23-30. [crossref]

6. Ramachandran A, Mary S, Yamuna A, Murugesan N, et al. (2008) High prevalence of diabetes and cardiovascular risk factors associated with urbanization in India. Diabetes Care 31: 893-898. [crossref]

7. Anjana RM, Deepa M, Pradeepa R, Mahanta J, et al. (2017) ICMR-INDIAB Collaborative Study Group. Prevalence of diabetes and prediabetes in 15 states of India: results from the ICMR-INDIAB population-based cross-sectional study. Lancet Diabetes Endocrinol 5(8): 585-596. [crossref]

8. Anjana RM, Shanthi Rani CS, Deepa M, Pradeepa R, et al. (2015) Incidence of Diabetes and Prediabetes and Predictors of Progression Among Asian Indians: 10 Year Follow-up of the Chennai Urban Rural Epidemiology Study (CURES). Diabetes Care 38(8): 1441-8. [crossref]

9. Mohan V (2019) Expanding the concept of 'Clinical Inertia' in diabetes. J Diabetol 10: 1-3.

10. World Health Organization. Definition and diagnosis of diabetes mellitus and intermediate hyperglycaemia: report of a WHO/IDF consultation. Geneva: World Health Organization 2006; 1-50. [crossref]

11. Use of glycated haemoglobin (HbAlc) in the diagnosis of diabetes mellitus. Diabetes Res Clin Pract.93: 299-309. [crossref]

12. Nanditha A, Ma RC, Ramachandran A, Snehalatha C, et al. (2016) Diabetes in Asia and the Pacific: Implications for the Global Epidemic. Diabetes Care 39: 472-85. [crossref]

13. Mathur R, Palla L, Farmer RE, Chaturvedi N, et al. (2020) Ethnic differences in the severity and clinical management of type 2 diabetes at time of diagnosis: A cohort study in the UK Clinical Practice Research Datalink. Diabetes Res Clin Pract 160: 108006. [crossref]

14. Mohan V, Shah SN, Joshi SR, Seshiah V, et al. (2014) DiabCare India 2011 Study Group. Current status of management, control, complications and psychosocial aspects of patients with diabetes in India: Results from the DiabCare India 2011 Study. Indian J Endocrinol Metab 18: 370-8. [crossref]

15. Winkley K, Thomas SM, Sivaprasad S, Chamley M, et al. (2013) The clinical characteristics at diagnosis of type 2 diabetes in a multi-ethnic population: the South London Diabetes cohort (SOUL-D). Diabetologia 56: 1272-81. [crossref]

16. Wright AK, Welsh P, Gill J, Kontopantelis E, et al. (2020) Age-, sex- and ethnicityrelated differences in body weight, blood pressure, $\mathrm{HbAlc}$ and lipid levels at the diagnosis of type 2 diabetes relative to people without diabetes. Diabetologia 63 : 1542-1553. [crossref]

17. Ramachandran A, Snehalatha C, Vijay V, Viswanathan M (1994) Underestimation of obesity in newly diagnosed non - insulin dependent diabetes subjects: A study from South India. Diabetes, Nutrition \& Metabolism V7 (4): 251-55. [crossref]

18. Sattar N, Gill JM (2015) Type 2 diabetes in migrant south Asians: mechanisms, mitigation, and management. Lancet Diabetes Endocrinol 3: 1004-16. [crossref]

19. Ramachandran A, Snehalatha C, Vijay V, Viswanathan M (1996) Diabetic retinopathy at the time of diagnosis of NIDDM in south Indian subjects. Diabetes Res Clin Pract 32(1-2): 111-4. [crossref]

Citation:

Arun Raghavan, Arun Nanditha, Krishnamoorthy Satheesh, Priscilla Susairaj, Ramachandran Vinitha, et al. (2020) The Profile of Clinically Diagnosed New Type 2 Diabetes among Asian Indians. Endocrinol Diabetes Metab J Volume 4(3): 1-4. 